\title{
Experimental Determination and Thermodynamic Correlation of 7-Amino-4-Methylcoumarin Solubility in Various Cosolvency Mixtures at (278.15 - 323.15) K
}

\author{
Yuli Shi1 ${ }^{1,2,}$, Haojian Zhang ${ }^{1}$, Xiaomin Hong ${ }^{1}$, Xiaodong Wang ${ }^{2}$ \\ ${ }^{1}$ School of Materials and Chemical Engineering, Ningbo University of Technology, Fenghua Road 201, Ningbo \\ 315016, Zhejiang, P.R. China \\ ${ }^{2}$ Chemical and Materials Engineering, School of Engineering, University of Aberdeen, Aberdeen AB24 3UE, \\ Scotland, United Kingdom
}

Corresponding author. Phone: + 86574 88918259; Fax: + 8657488918259.

E-mail address: yuli_shi@tju.edu.cn 
ABSTRACT: Four solvents (ethanol, isopropanol, ethylene glycol (EG) and N,N-dimethyl formamide (DMF)) that can be mixed with water in any ratio were selected to determine the dissolution performance of 7-amino-4-methylcoumarin by the classical shake-flask method. The measured temperature range began at 278.15 and ended at $303.15 \mathrm{~K}$, and the pressure environment was controlled at standard atmospheric pressure $(101.1 \mathrm{kPa})$. Results reveal that with the addition of organic solvents, the solubilization effect of the 7-amino-4-methylcoumarin was very significant, and the larger the amount of addition, the more obvious the effect of solubilization. Not only that, the temperature change had a non-negligible effect on the dispersion of 7-amino-4-methylcoumarin, the temperature increases monotonically, and the better the dissolution. When the external conditions were kept constant, the addition of DMF made the solubilization effect of 7-amino-4-methylcoumarin most obvious among all the organic solvents used. This study involved three models including the Jouyban-Acree model and its two variants (van't Hoff-Jouyban-Acree model and Apelblat-Jouyban-Acree model) were used to correlate the solubility data of 7-amino-4-methylcoumarin in aqueous cosolvent mixtures. The RAD and RMSD reaches to $3.47 \times 10^{-2}$ and $1.79 \times 10^{-3}$ rooting in the van't Hoff-Jouyban-Acree model. The relevant parameters obtained through model calculation and experimental means are essential for product synthesis, separation and purification processes.

\section{- INTRODUCTION}

The aqueous solubility is a vital physicochemical property in the pharmaceutical drug development, however, poor solubility of them has brought many problems and limited further application in some drug delivery issues. ${ }^{1-3}$ Solubility enhancement of low or insoluble drugs is one of the most significant means in drug discovery, improving bioavailability, dose reduction and efficiency and chemical processes design..$^{3-9}$ As one of the important representative of coumarin derivatives, 7-amino-4-methylcoumarin $\quad\left(\mathrm{C}_{10} \mathrm{H}_{9} \mathrm{NO}_{2}\right.$, CAS No. 26093-31-2, also named 
4-methyl-7-aminocoumarin or Coumarin 120 , molecular weight $175.18 \mathrm{~g} \cdot \mathrm{mol}^{-1}$, abbreviated as 7-AMC, chemical structure shown in Figure 1 of supporting information), a beige to brown crystalline powder, that is the important fluorescent substance successfully applied in diversified performance areas ${ }^{10-14}$ i.e. microbial detection, immunoassay, biochemical enzymology and polypeptide synthesis owing to active 7-position amino group. It has strong fluorescence properties in the visible region which is widely used as fluorescent whitening agents, fluorescent indicators, fluorescent dyes and laser dyes, that attracted much attention in recent years in the development of new organic electroluminescent materials, solar cells, organic dye photosensitizers and biological probes. ${ }^{15-19}$

In the natural state, the 7-AMC is very unsatisfactory as an organic drug dissolved in water, such a situation greatly affects its absorption in the small intestine, resulting in a particularly low bioavailability. More importantly, understanding the dissolution data of drugs in common solvents is an important reference for crystallization separation, extraction and other operations. ${ }^{8,20,21}$ There are many ways to obtain a drug with higher purity and a more beautiful appearance. The method of adding an organic solvent to water to change the solubility of the drug is not only efficient but also inexpensive, and most importantly, the operation of the method is relatively simple. ${ }^{22-24}$ The preferred solvent used to recrystallize the crude product in Refs (10-12) is ethanol. In terms of the selection principle of the mixed solvent, the selected solvent should satisfy three conditions including steady, non-toxic, and inexpensive. ${ }^{25}$ Numerous available solvents such as ethanol, isopropanol, dimethyl sulfoxide (DMSO), $N, N$-dimethylformamide (DMF), polyethylene glycols and etc. ${ }^{21,23,26}$ To the best of our knowledge, prior to this, no relevant scientific researcher systematically explored the dissolution of 7-AMC, so this work system measured the dissolution data in the mixed solvents, filling the gap in this field. The acquisition of these data is very practical for the fine chemical industry and the biopharmaceutical industry, and has strongly promoted the development of the pharmaceutical industry. 


\section{口 EXPERIMENTAL SECTION}

Materials, Apparatus and Methods. The development, production and distribution of 7-AMC is completed by Shanghai Haohong Biomed. Tech. Co., Ltd. The label on the reagent bottle indicates that the purity of the drug is mass fraction $\geqslant 0.98$. In order to ensure the accuracy of the experimental data, the purchased drug 7-AMC was dissolved in ethanol and then recrystallized. The above operation was repeated three times, and the final product concentration was 0.995 in mass fraction confirmed by a high-performance liquid phase chromatograph (HPLC, Agilent-1260). All organic solvents (ethanol, isopropanol, EG and DMF) are developed and produced by Aladdin Reagent Co., Ltd., Shanghai. The purity of the reagent bottle label indicates that the mass fraction is greater than 0.995. After verification by gas chromatography (GC, FULI 9790, China), the data on the label is found to be authentic. The twice distilled deionized water (conductivity $<2 \mu \mathrm{S} \cdot \mathrm{cm}^{-1}$ ) was prepared in our laboratory. The information on all the drugs and reagents involved in this experiment is detailed in Table 1. The various components of the device used in this experiment were vividly drawn in Figure 2 of Supporting Information, the construction principle of this experimental device is almost the same as the principle of the equipment used in the previous experiment. ${ }^{26}$ Nevertheless, it is necessary to briefly introduce the functions of the various components of the experimental device. The functions of the experimental apparatus can be mainly divided into three categories, including dissolution, stirring and temperature control. The dissolution process is mainly carried out in a jacketed glass instrument with a capacity of $100 \mathrm{ml}$. The main function of the agitation process is to help dissolve the drug. This process is also carried out in the glass container just mentioned, in which a magnetic stirrer is placed and driven by the magnetic stirrer below to achieve the purpose of stirring. The main function of the temperature control process is to ensure that the dissolution process is carried out in a constant temperature environment, which is mainly accomplished by the cooperation of the thermostatic bath (Shanghai Joyn Electronic Co., Ltd., China, Model: QYHX-1030, standard uncertainty: $0.05 \mathrm{~K}$ ) and the circulating 
fluid (water + isopropanol). The circulating fluid flows from the water bath through the interlayer of the glass instrument to achieve the purpose of the dissolution process at a constant temperature. In order to further enhance the precise control of the dissolution temperature, a mercury glass micro thermometer (standard uncertainty: $0.02 \mathrm{~K}$ ) is inserted into the solution during the dissolution process. The organic solvent is a volatile liquid, and it is necessary to add a cover to the glass container during the dissolution process in order to prevent the total amount of the organic solvent from being lost. An analytical balance (Satorius Scientific Instrument (Beijing), model: BSA224S, standard uncertainty: $0.0001 \mathrm{~g}$ ) was employed to determine the mass of the solute, solvent, and saturated solution.

Preparation of Cosolvency Systems. In the process of preparing a mixture of organic solvent and water according to a certain ratio, the analytical balance (model: BSA224S) is the implementation of the beginning and the end. The quality of the mixture prepared each time is controlled at $50 \mathrm{~g}$ (standard uncertainty: $0.0001 \mathrm{~g}$ ). The ratio of organic solvent to water starts at 0 and increases at a rate of 0.1 until it increases to 1 . The organic solvent is a volatile liquid, and it is necessary to add a cover to the glass container during the dissolution process in order to prevent the total amount of the organic solvent from being lost at $101.1 \mathrm{kPa}$. The concentration of 7-AMC (mole fraction $x_{\mathrm{w}, \mathrm{T}}$ ) in the mixed solvents is obtained from Eq. (1), and The composition (w) of the binary mixed solvent is obtained by Eqs. (2) and (3).

$$
\begin{aligned}
& x_{\mathrm{w}, \mathrm{T}}=\frac{m_{1} / M_{1}}{m_{1} / M_{1}+m_{2} / M_{2}+m_{3} / M_{3}} \\
& w_{1}=\frac{m_{2}}{m_{2}+m_{3}} \\
& w_{2}=\frac{m_{3}}{m_{2}+m_{3}}
\end{aligned}
$$

Here, $m_{1}, m_{2}$ and $m_{3}$ represent the mass of 7-AMC, organic solvents and water, respectively. $M_{1}$, $M_{2}$ and $M_{3}$ are the corresponding molar mass. 
Solubility Investigation. The dispersion performance of 7-AMC in mixed solvents of ethanol + water, isopropanol + water and so on is determined by the shake-flask method ${ }^{8,27-30}$, and the mole fraction of the solute in the steady state of the solution is accurately calculated by modern analytical instrument HPLC (Agilent-1260). The place where the saturated solution of 7-AMC is obtained in each experiment is in a jacketed glass container. Approximately $50 \mathrm{~g}$ of mixed solvent and a certain amount of 7-AMC are added to the glassware, and the amount of 7-AMC is required to ensure that there is remaining after the solution is saturated. Stirring is essential during the preparation of the saturated solution, on the grounds that it is difficult to ensure that the solute and the solvent can be uniformly mixed and saturated in the natural state. In addition, the dissolution process needs to be carried out in a relatively stable temperature environment, which relies on circulating fluid flowing between the jacketed glass instrument and the thermostatic bath. The next step is to find the equilibrium point of dissolution. Take $1 \mathrm{ml}$ of solution by $2 \mathrm{ml}$ of preheated syringe equipped with a pore syringe filter (PTFE $0.2 \mu \mathrm{m}$ ) every 1 hour and transfer it to a volumetric flask to dilute the volume and then analyzed by HPLC. When the results derived by HPLC are the same three times in succession, it can be basically determined that the dissolution system has reached a steady state. Furthermore, it is also an important part to obtain the time when the dissolution of the solute reaches the dynamic equilibrium. The two commonly used methods are the precipitation solute method and the increased solute method. When the two methods achieve consistent results, the results can be considered scientifically valid. The results showed that it spent about $18 \mathrm{~h}$ to be equilibrium and then the stirrer was turned off. While waiting for the solute suspended in the solution to completely settle to the bottom of the container, the clear solution is quickly transferred to a $25 \mathrm{ml}$ volumetric flask and diluted to volume. After shaking, it is analyzed by HPLC.

Analysis Method. As a commonly used quantitative analytical instrument, Agilent-1260 HPLC was selected to determine the content of 7-AMC this time. The following is a brief introduction to the configuration. The chromatographic column is a type LP-C18 $(250 \mathrm{~mm} \times 4.6 \mathrm{~mm})$ reverse 
column and the usual operating temperature setting is still $303 \mathrm{~K}$. The maximum absorption wavelength of the UV-vis detector was $210 \mathrm{~nm}$. The mobile phase used this time is chromatographically pure methanol without adding any other solvent with a flow rate of 0.8 $\mathrm{ml} \cdot \mathrm{min}^{-1}$. The results of the analysis should be noted that each sample should be measured three times under the same conditions. If the three data are not much different, their mean values are taken. If the deviation is large, it needs to be re-measured until scientific results are obtained (relative standard uncertainty: 0.025).

XPRD of 7-AMC Solid Phase. The X-ray powder diffraction (XPRD) is a commonly used instrument for qualitative analysis of drug crystal forms, which is often favored because of its simplicity and accuracy. The 7-AMC solid crystal form precipitated at the bottom during the experiment was also analyzed by XPRD (Bruker AXS D8 Advance, Germany). The samples were determined by $\mathrm{Cu} \mathrm{Ka}$ radiation $(\lambda=1.54184 \mathrm{~nm})$, and the tube voltage $40 \mathrm{kV}$ and tube current 30 $\mathrm{mA}$, respectively. The diffraction angle (2-Theta) starts at $5^{\circ}$, increases at a rate of $5^{\circ}$ per minute, and ends when the diffraction angle reaches $80^{\circ}$ at room temperature under atmospheric pressure.

\section{- RESULTS AND DISCUSSION}

XPRD Characteristic. In the dissolution process, since the nature of the solvent and the solute are differentiated, the possibility of a chemical reaction between the solvent and the solute is not excluded. In order to eliminate this interference term, XPRD was used to characterize 7-AMC. The patterns of the raw material and the all crystal samples are plotted in Figure 3 of supporting information. The effective information that can be obtained from it is that almost every shape of the map, the position and size of the characteristic peaks are almost the same as the raw materials. This is a powerful proof that there is no chemical reaction between 7-AMC and the solvent chosen, and the crystal shape of the solute itself does not change.

Experimental Solubility. The equilibrium mole fraction of 7-AMC in four aqueous cosolvent solutions are listed in Tables 2, 3, 4 and 5. The dissolution effect of temperature and organic 
solvent addition on 7-AMC is also vividly drawn in Figures. 1-4. It can be seen from Tables 2-5 that The higher the temperature rise, the less difficult the dissolution of 7-AMC is, and the smaller the amount of organic solvent added, the more difficult it is to dissolve. The addition of DMF made the solubilization effect of 7-AMC most obvious among all the organic solvents used under fixed conditions.

The dissolution performance of 7-AMC in various mixed solvents varies, because the physical-chemical properties of various solvents vary widely. DMF is the most polar in terms of the polarity of the four organic solvents used this time, which results in the best dissolution of 7-AMC in a mixed solvent of DMF and water. At the same time, EG is one of the protic non-polar solvents, resulting in a lower amount of 7-AMC dissolved in the EG aqueous solution.

\section{— THERMODYNAMIC COSOLVENCY MODELS}

The mixed solution system is already a relatively common system in all dissolution systems. In the past reports ${ }^{21,23,28}$, there are some thermodynamic models suitable for mixed dissolution systems, such as Jouyban-Acree model ${ }^{21,23,31}$, van't Hoff-Jouyban-Acree model with equation ${ }^{21,23,32}$ and Jouyban-Acree model combined with modified Apelblat equation²1,23,33,34.

Jouyban-Acree Model. The Jouyban-Acree model is given as Eq. (4).

$$
\ln x_{\mathrm{w}, \mathrm{T}}=w_{1} \ln x_{1, \mathrm{~T}}+w_{2} \ln x_{2, \mathrm{~T}}+\frac{w_{1} w_{2}}{T / \mathrm{K}} \sum_{\mathrm{i}=0}^{2} J_{\mathrm{i}}\left(w_{1}-w_{2}\right)^{\mathrm{i}}
$$

where $x_{\mathrm{w}, \mathrm{T}}$ denotes the solubility of 7-AMC in solvent mixtures; $w_{1}$ and $w_{2}$ are the mass fraction of organic solvents and water; $x_{1, \mathrm{~T}}$ and $x_{2, \mathrm{~T}}$ are the mole fraction of 7-AMC in pure solvents; and $J_{\mathrm{i}}$ are the Jouyban-Acree model parameters.

Van't Hoff-Jouyban-Acree Model. The Van't Hoff equation introduces the reciprocal of temperature, and the mole fraction of the solute is linear with the reciprocal of temperature.

$$
\ln x_{\mathrm{T}}=A+\frac{B}{T / \mathrm{K}}
$$


Combining Eq. (4) and Eq. (5), the van't Hoff-Jouyban-Acree model can be derived ${ }^{21,23,32}$ and expressed as Eq. (6).

$$
\ln x_{\mathrm{w}, \mathrm{T}}=w_{1}\left(A_{1}+\frac{B_{1}}{T / \mathrm{K}}\right)+w_{2}\left(A_{2}+\frac{B_{2}}{T / \mathrm{K}}\right)+\frac{w_{1} w_{2}}{T / \mathrm{K}} \sum_{i=0}^{2} J_{i}\left(w_{1}-w_{2}\right)^{i}
$$

$A_{1}, B_{1}, A_{2}, B_{2}$ and $J_{\mathrm{i}}$ are equation parameters.

Modified Apelblat-Jouyban-Acree Model. The modified Apelblat equation is described as Eq.

$$
\ln x_{\mathrm{T}}=A+\frac{B}{T / K}+C \ln (T / K)
$$

$A, B$, and $C$ are equation parameters; and also $x_{\mathrm{T}}$ is the mole fraction solubility of 7-AMC

By substituting Eq. (7) into Eq. (4), the modified Apelblat-Jouyban-Acree model is obtained $^{21,23,33,34}$

$$
\ln x_{\mathrm{w}, \mathrm{T}}=w_{1}\left[A_{1}+\frac{B_{1}}{T / \mathrm{K}}+C_{1} \ln (T / K)\right]+w_{2}\left[\left(A_{2}+\frac{B_{2}}{T / \mathrm{K}}+C_{2} \ln (T / K)\right]+\frac{w_{1} w_{2}}{T / \mathrm{K}} \sum_{i=0}^{2} J_{\mathrm{i}}\left(w_{1}-w_{2}\right)^{\mathrm{i}}\right.
$$

Eqs. (4), (6) and (8) are the mathematical expressions of the three models respectively, and the experimental data is brought into the expression to obtain the corresponding model parameters by means of nonlinear regression. During the regression process, the objective function is defined as

$$
F=\sum_{\mathrm{i}=1}\left(\ln x_{\mathrm{i}}^{\mathrm{e}}-\ln x_{\mathrm{i}}^{\mathrm{c}}\right)^{2}
$$

In addition, the relative average deviation $(R A D)$ and root-mean-square deviation $(R M S D)$ are employed and described as Eqs. (10) and (11).

$$
\begin{aligned}
& R A D=\frac{1}{N} \sum\left(\frac{\left|x_{\mathrm{w}, \mathrm{T}}^{\mathrm{c}}-x_{\mathrm{w}, \mathrm{T}}^{\mathrm{e}}\right|}{x_{\mathrm{w}, \mathrm{T}}^{\mathrm{e}}}\right) \\
& R M S D=\sqrt{\frac{\sum_{i=1}^{N}\left(x_{\mathrm{w}, \mathrm{T}}^{\mathrm{c}}-x_{\mathrm{w}, \mathrm{T}}^{\mathrm{e}}\right)^{2}}{N}}
\end{aligned}
$$

where $N$ is the number of experimental data points. $x_{\mathrm{w}, \mathrm{T}}^{\mathrm{e}}$ represents the experimental value; and 
$x_{\mathrm{w}, \mathrm{T}}^{\mathrm{c}}$ is the calculated value.

All the formula calculations involved in this paper and the regression of related parameters are realized by Mathcad software. All calculations including associated model parameter values together with the $R A D$ and the $R M S D$ are detailed in Table 6. In order to vividly show the difference between the calculated values of the model and the experimental values, the solubility data of 7-AMC in cosolvent mixtures of (ethanol + water), (isopropanol + water), (EG + water) and $(\mathrm{DMF}+$ water) calculated by the Jouyban-Acree model is also added in Figures 1-4. Table 6 shows that the maximum value of $R A D$ is $3.47 \%$ from the van't Hoff-Jouyban-Acree model for ethanol + water. Similarly, the $R M S D$ are no more than $1.79 \times 10^{-3}$. Among all the selected models, the data derived by the Jouyban-Acree model is closest to the experimental results. Not only that, but the settlement results of the other two models can also be considered scientific and effective for the experimental results.

\section{- CONCLUSION}

The four organic solvents are mutually soluble with water in a certain ratio to form a stable mixed liquid, and the solute 7-AMC is dissolved in the above mixed liquid and the mole fraction of 7-AMC after stabilization was determined with the classical shake-flask method. The measured temperature range began at 278.15 and ended at $303.15 \mathrm{~K}$, and the pressure environment was controlled at standard atmospheric pressure $(101.1 \mathrm{kPa})$. Results reveal that with the addition of organic solvents, the solubilization effect of the 7-AMC was very significant, and the larger the amount of addition, the more obvious the effect of solubilization. Not only that, the temperature change had a non-negligible effect on the dispersion of 7-AMC, the temperature increases monotonically, and the better the dissolution. A total of three models were selected to calculate the dispersion concentration of 7-AMC. The $R A D$ and $R M S D$ were no more than $3.47 \times 10^{-2}$ and $1.79 \times 10^{-3}$, respectively. The addition of the organic solvent effectively reduces the difficulty of 
dispersing the solute, especially when the proportion of the organic solvent exceeds 0.5 . The most eye-catching is that when the DMF ratio is 1 , the dispersion of solute reaches a maximum.

\section{- ASSOCIATED CONTENT}

\section{(S) Supporting Information}

Supporting Information Available: Chemical structure of 7-AMC (Figure S1), experimental apparatus (Figure S2), XRD patterns (Figure S3).

\section{- AUTHOR INFORMATION}

\section{Corresponding author}

*Phone: + 86574 88918259; Fax:+86574 88918259. E-mail address: yuli_shi@tju.edu.cn.

\section{ORCID}

Yuli Shi: 0000-0003-3891-920X

Haojian Zhang: 0000-0003-2541-8596

\section{Funding}

This research was supported by Zhejiang Provincial Natural Science Foundation of China under Grant No. Y17B060016. The author gratefully acknowledges the support of K. C. Wong Education Foundation.

\section{Notes}

The authors declare no competing financial interest.

\section{REFERENCES}

(1) Rosen, H. and Abribat, T. The Rise and Rise of Drug Delivery. Nat. Rev. Drug Discov. 2005, 4, $381-385$.

(2) Hirano, A.; Arakawa, T.; Shiraki, K. Arginine Increases the Solubility of Coumarin: Comparison with Salting-in and Salting-out Additives. J. Biochem. 2008, 144, 363-369.

(3) Hatefi, A.; Jouyban, A.; Mohammadian, E.; Acree, W. E.; Rahimpour, E. Prediction of 
Paracetamol Solubility in Cosolvency Systems at Different Temperatures. J. Mol. Liq. 2019, 273, $282-291$.

(4) Mohammadian, E.; Barzegar-Jalali, M.; Rahimpour, E. Solubility Prediction of Lamotrigine in Cosolvency Systems Using Abraham and Hansen Solvation Parameters. J. Mol. Liq. 2019, 276, $675-679$.

(5) Chaudhary, A.; Nagaich, U.; Gulati, N.; Sharma, V. K.; Khosa, R. L. Enhancement of Solubilization and Bioavailability of Poorly Soluble Drugs by Physical and Chemical Modifications: A Recent Review. J. Adv. Pharm. Edu. Res. 2012, 2, 32-67.

(6) Li, R. Water-Insoluble Drug Formulation (Second Edition), CRC Press: Boca Raton, FL, 2008.

(7) Rathi, P.; Jouyban, A.; Khoubnasabjafari, M.; Kale, M. Solubility of Etoricoxib in Aqueous Solutions of 1,4-Butanediol, 1,4-Dioxane, $N, N$-Dimethylacetamide, $N, N$-Dimethylformamide, Dimethyl Sulfoxide, and Ethanol at 298.2 K. J. Chem. Eng. Data. 2015, 60, 2128-2134.

(8) Sardari, F.; Jouyban, A. Solubility of Nifedipine in Ethanol + Water and Propylene Glycol + Water Mixtures at 293.2 to 313.2 K. Ind. Eng. Chem. Res. 2013, 52, 14353-14358.

(9) Zhang, P. S.; Zhao, R.; Zhang, C.; Wan, Y. M.; Li, T.; Ren, B. Z. Thermodynamic Analysis and Correlation of Cyromazine in Three (Acetic Acid, Propanoic Acid or Ethylene Glycol + Water) Binary Solvents at Different Temperatures. J. Mol. Liq. 2018, 272, 158-169.

(10) Ge, W. G.; Zhou, L. The Synthesis of 7-Amino-4-methylcoumarin. Acta Medicinae Sinica. 1998, 11, 19-20. (Chinese)

(11) Atkins, R. L.; Bliss, D. E. Substituted Coumarins and Azacoumarins. Synthesis and Fluorescent Properties. J. Org. Chem. 1978, 43, 1975-1980.

(12) Wu, Q. P.; Ma, Y. X.; Zhang, J. M.; Wei, X. H. Progress in syntheses of coumarin fluorogenic substrates and their application in microbial detections. Chem. Ind. Eng. Prog. 2014, 33, 2444-2449. (Chinese)

(13) Yin, C. X.; Huo, F. J.; Yang, Y. T. Reagent and method for detecting cysteine. CN Patent 103,788,076, May 14, 2014.

(14) Huang J.; Yang, B. Method for preparing modified graphene-polymethyl methacrylate 
composite film. CN Patent 105,237,930, Jun 13, 2016.

(15) Huang, L.; Cheng, J.; Xie, K. F.; Xi, P. X. Cu(2+)-Selective Fluorescent Chemosensor Based on Coumarin and Its Application in Bioimaging. Dalton Transactions. 2011, 40, 10815-10817.

(16) Tsukamoto, K.; Shinohara, Y.; Lwasaki S.; Maeda, H. A Coumarin-Based Fluorescent Probe for $\mathrm{Hg}^{2+}$ and $\mathrm{Ag}^{2+}$ with an $\mathrm{N}^{\prime}$-Acetylthioureido Group as A Fluorescence Switch. Chem. Commun. 2011, 47, 5073-5075.

(17) Ma, Y.; Luo, W.; Quinn, P. J.; Liu, Z.; Hider, R. C. Synthesis, Physicochemical Properties, and evaluation of Novel Iron Chelators with Fluorescent Sensors. Med. Chem. 2004, 47, 6349-6362.

(18) Brunet, E.; Garcia-Losada, P.; Rodriguez-Ubis, J-C.; Juanes, O. Synthesis of New Fluorophores Derived from Monoazacrown Ethers and Coumarin Nucleus. Canadian. J. Chem. 2002, 80, 169-174.

(19) Yesilada, E.; Taninaka, H.; Takaishi, Y.; Honda, G.; Sezik, E.; Momota, H.; et al. In Vitro Inhibitory Effects of Daphne Oleoides Ssp. Oleoides on Inflammatory Cytokines and Activity-Guided Isolation of Active Constituents. Cytokine. 2001, 13, 359-364.

(20) Prausnitz, J. M.; Tavares, F. W. Thermodynamics of Fluid-Phase Equilibria for Standard Chemical Engineering Operations. AIChE J. 2004, 50, 739-761.

(21) Jouyban, A. Handbook of Solubility Data for Pharmaceuticals. CRC Press, BocaRaton, FL, 2010.

(22) Kumar, P.; Singh, C. A Study on Solubility Enhancement Methods for Poorly Water Soluble Drugs. Am. J. Pharmacol. Sci. 2013, 1, 67-73.

(23) Jouyban, A. Review of the Cosolvency Models for Predicting Solubility of Drugs in Water-Cosolvent Mixtures. J. Pharm. Pharmaceut. Sci. 2008, 11, 32-58.

(24) Chaudhary, A.; Nagaich, U.; Gulati, N.; Sharma, V. K.; Khosa, R. L. Enhancement of Solubilization and Bioavailability of Poorly Soluble Drugs. J. Adv. Pharmacy Edu. \& Res. 2012, 2, $32-67$. 
(25) Jouyban, A.; Chew, N. Y. K.; Chan, H. K.; Sabour, M.; Acree, W. E. Jr.; A Unified Cosolvency Model for Calculating Solute Solubility in Mixed Solvents. Chem. Pharm. Bull. 2005, $53,634-637$.

(26) Wang, H. J.; Yao, G. B,; Zhang, H. J. Measurement and Correlation of the Solubility of Baicalin in Several Mixed Solvents. J. Chem. Eng. Data. 2019, 64, 1281-1287.

(27) Baka, E.; Comer, J. E. A.; Krisztina, Takács-Novák. Study of Equilibrium Solubility Measurement by Saturation Shake-Flask Method Using Hydrochlorothiazide as Model Compound. J. Pharmaceut. Biomed. 2008, 46, 335-341.

(28) Jouyban, A.; Nozohouri, S.; Martinez, F. Solubility of Celecoxib in \{2-Propanol (1) + Water (2) Mixtures at Various Temperatures: Experimental Data and Thermodynamic Analysis. J. Mol. Liq. 2018, 254, 1-7.

(29) Fang, J.; Zhang, M. J.; Zhu, P. P.; Ouyang, J. B.; Gong, J. B.; Chen, W.; Xu, F. X. Solubility and Solution Thermodynamics of Sorbic Acid in Eight Pure Organic Solvents. J. Chem. Thermodyn. 2015, 85, 202-209.

(30) Zhou, L. P.; Yang, L. H.; Tilton, S.; Wang, J. L. Development of A High Throughput Equilibrium Solubility Assay Using Miniaturized Shake-Flask Method in Early Drug Discovery. $J$. Pharm. Sci-US. 2007, 96, 3052-3071.

(31) Jouyban, A.; Acree, W. E. Mathematical Derivation of the Jouyban-Acree Model to Represent Solute Solubility Data in Mixed Solvents at Various Temperatures. J. Mol. Liq. 2018, 256, 541-547.

(32) Jouyban, A.; Fakhree, M. A. A.; Acree, W. E. Comment on "Measurement and Correlation of Solubilities of (Z)-2-(2-Aminothiazol-4-yl)-2-Methoxyiminoacetic Acid in Different Pure Solvents and Binary Mixtures of Water + (Ethanol, Methanol, or Glycol). J. Chem. Eng. Data. 2012, 57, 1344-1346.

(33) Apelblat, A.; Manzurola, E. Solubilities of o-Acetylsalicylic, 4-Aminosalicylic, 
3,5-Dinitrosalicylic, and $p$-Toluic Acid, and Magnesium-DL-Aspartate in Water from $T=(278$ to 348) K. J. Chem. Thermodyn. 1999, 31, 85-91.

(34) Apelblat, A.; Manzurola, E. Solubilities of L-Glutamic Acid, 3-Nitrobenzoic Acid, p-Toluic Acid, Calcium-L-Lactate, Calcium Gluconate, Magnesium-DL-Aspartate, and Magnesium-L-Lactate in Water. J. Chem. Thermodyn. 2002, 34, 1127-1136. 


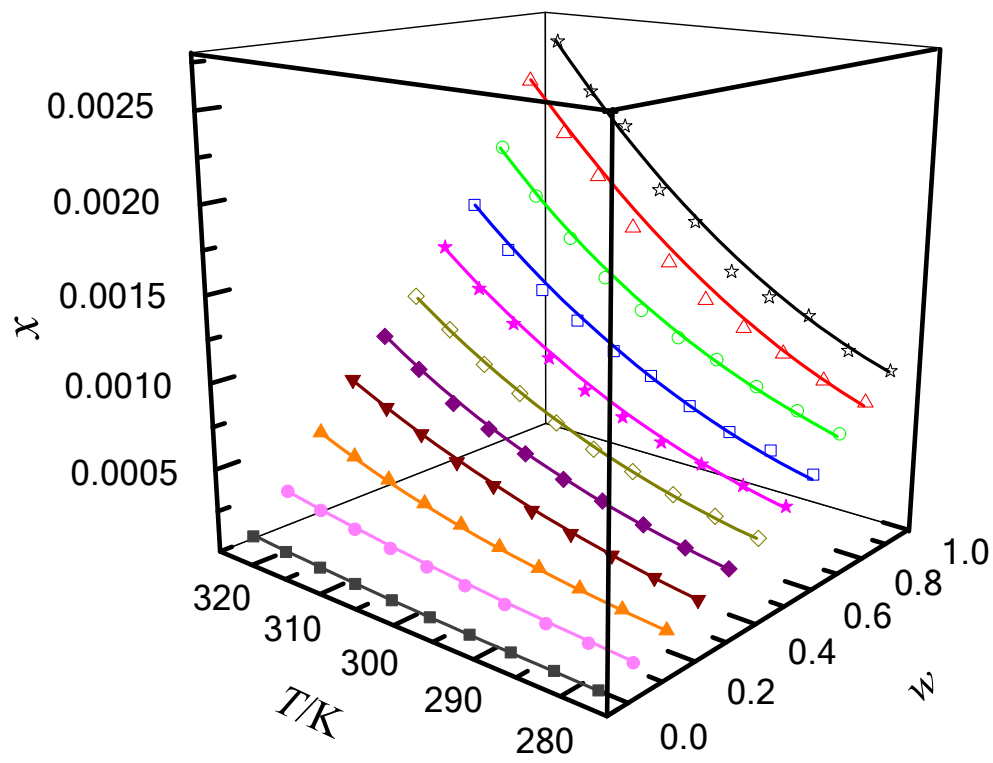

Figure 1. Equilibrium solubility $(x)$ of $7-A M C$ in ethanol $(w)+$ water $(1-w)$ solutions with various mass fractions at different temperatures: $w$, mass fraction of ethanol; $\downarrow$, $w=1 ; \triangle, w=0.9000 ; \circ, w=0.7988 ; \square, w=0.7002 ; \star$, $w=0.6000 ; \diamond, w=0.5012 ; \diamond, w=0.4011 ; \nabla, w=0.3000 ; \boldsymbol{\Delta}, w=0.2010 ; \bullet, w=0.1000 ; \mathbf{\square}, w=0 ;-$, calculated curves by the Jouyban-Acree model. 


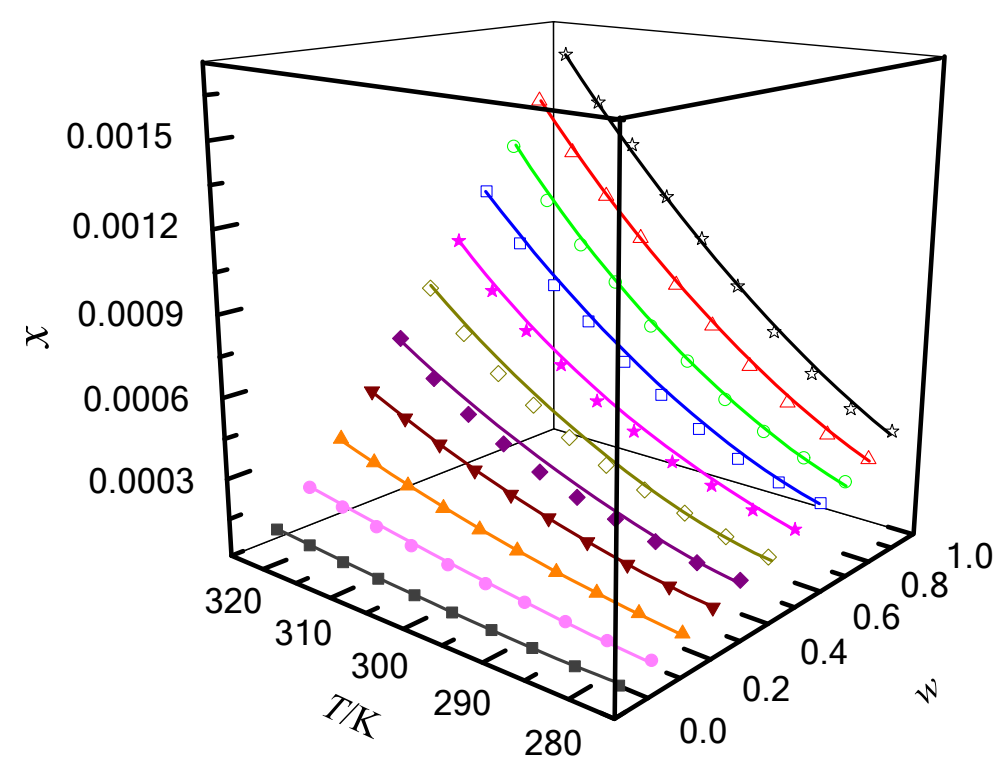

Figure 2. Equilibrium solubility $(x)$ of $7-\mathrm{AMC}$ in $\mathrm{EG}(w)+$ water $(1-w)$ solutions with various mass fractions at different temperatures: $w$, mass fraction of EG; $\mathcal{2}, w=1 ; \Delta, w=0.8979 ; \circ, w=0.8009 ; \square, w=0.7006 ; \star, w=0.6001 ; \diamond$, $w=0.5000 ; \bullet, w=0.3976 ; \mathbf{\nabla}, w=0.3011 ; \boldsymbol{\Lambda}, w=0.2000 ; \bullet, w=0.1003 ; \boldsymbol{\square}, w=0 ;-$, calculated curves by the Jouyban-Acree model. 


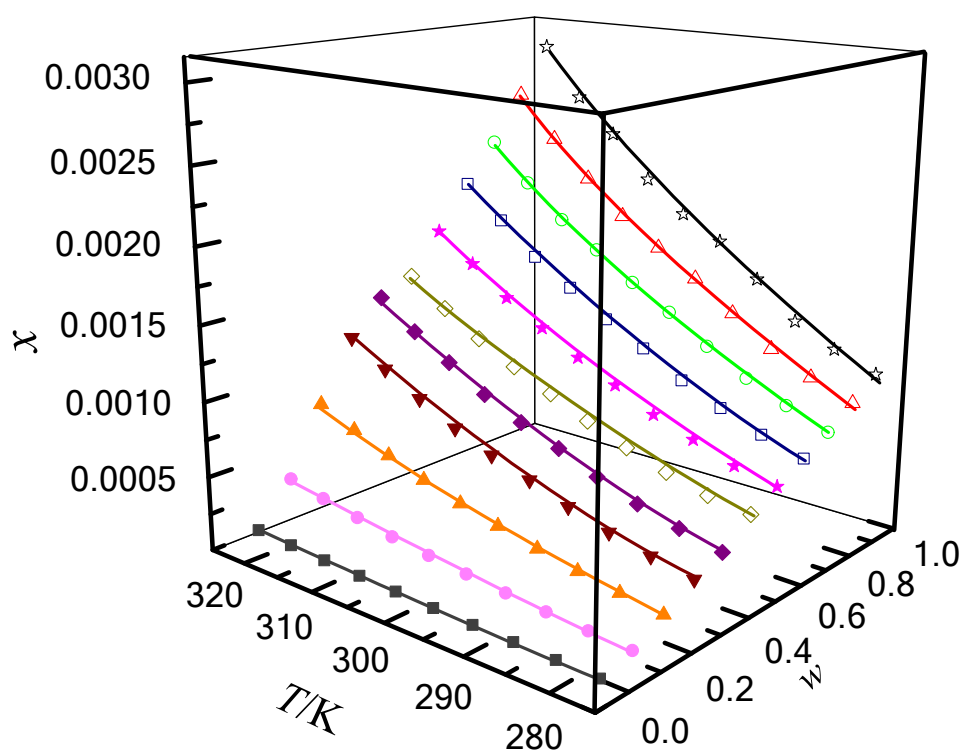

Figure 3. Equilibrium solubility $(x)$ of $7-\mathrm{AMC}$ in isopropanol $(w)+$ water $(1-w)$ solutions with various mass fractions at different temperatures: $w$, mass fraction of isopropanol; 弥, $w=1 ; \triangle, w=0.9013 ; \circ, w=0.8006$; $\square$, $w=0.7020 ; \star, w=0.5986 ; \diamond, w=0.5000$

$\diamond, w=0.3989$;

$\mathbf{\nabla}, w=0.3012$

$\boldsymbol{\Lambda}, w=0.2001 ; \bullet, w=0.1000$

-,$w=0 ;$,

calculated curves by the Jouyban-Acree model. 


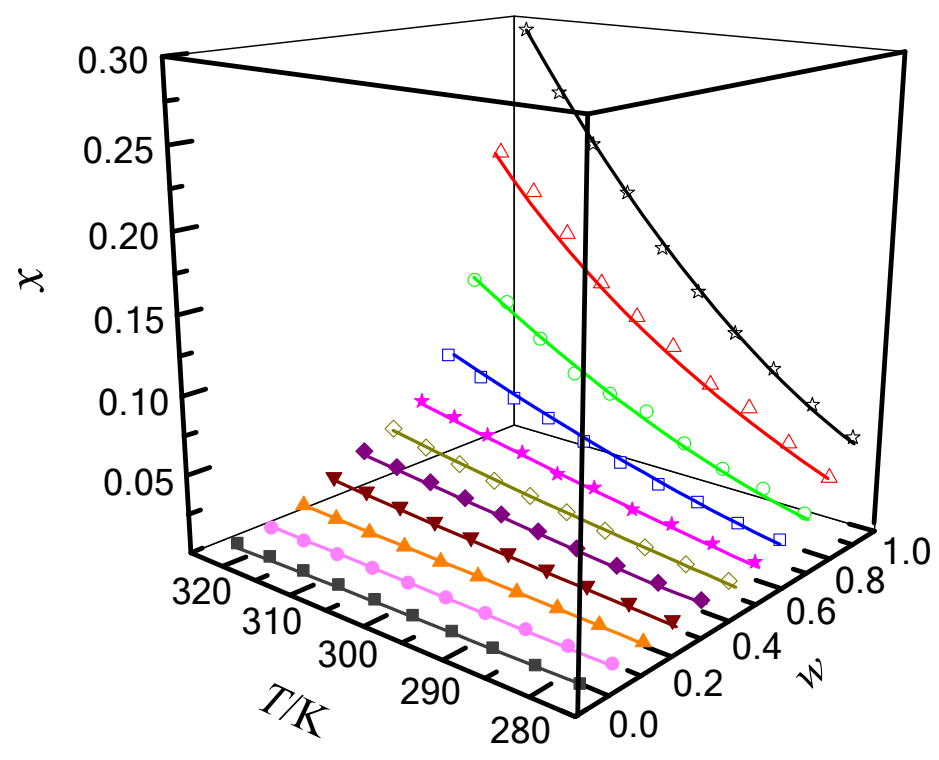

Figure 4. Equilibrium solubility $(x)$ of 7-AMC in DMF $(w)+$ water $(1-w)$ solutions with various mass fractions at different temperatures: $w$, mass fraction of DMF; 败, w=1; $\triangle, w=0.9009 ; \circ, w=0.7998 ; \square, w=0.7001 ; \star$, $w=0.6013 ; \diamond, w=0.5000 ; \diamond, w=0.4000 ; \mathbf{\nabla}, w=0.2990 ; \boldsymbol{\Lambda}, w=0.2003 ; \bullet, w=0.1002 ; \boldsymbol{\square}, w=0 ;$, calculated curves by the 


\section{Table 1}

Chemicals, purity and properties of the materials employed in this work.

\begin{tabular}{|c|c|c|c|c|c|}
\hline Chemicals & $\begin{array}{l}\text { Molar } \\
\text { mass } \\
\left(\mathrm{g} \cdot \mathrm{mol}^{-1}\right)\end{array}$ & Source & $\begin{array}{l}\text { Mass fraction } \\
\text { purity }\end{array}$ & $\begin{array}{l}\text { Purification } \\
\text { method }\end{array}$ & Analytical method \\
\hline $\begin{array}{l}\text { 7-Amino-4-methylcoumari } \\
\text { n (7-AMC) }\end{array}$ & 175.2 & $\begin{array}{l}\text { Shanghai } \\
\text { Haohong Biomed. } \\
\text { Tech. Co., Ltd. }\end{array}$ & 0.9950 & Recrystallization & HPLC $^{a}$ \\
\hline Ethanol & 46.07 & & 0.9950 & None & $\mathrm{GC}^{\mathrm{b}}$ \\
\hline Isopropanol & 60.06 & $\begin{array}{l}\text { Aladdin Industrial } \\
\text { (Shanghai) Co., }\end{array}$ & 0.9960 & None & GC \\
\hline Ethylene glycol & 62.07 & Ltd. & 0.9950 & None & $\mathrm{GC}$ \\
\hline$N, N$-Dimethylformamide & 73.10 & & 0.9970 & None & $\mathrm{GC}$ \\
\hline Water & 18.02 & Our lab & $\begin{array}{l}\text { Conductivity } \\
<2 \mu \mathrm{S} \cdot \mathrm{cm}^{-1}\end{array}$ & Twice distillation & $\begin{array}{l}\text { Conductivity } \\
\text { meter }\end{array}$ \\
\hline
\end{tabular}

${ }^{a}$ High-performance liquid chromatography.

${ }^{\mathrm{b}}$ Gas chromatography. 


\section{Table 2}

Equilibrium mole fraction $\left(x_{T, w}^{e} \times 10^{3}\right)$ of 7 -AMC ethanol $(w)+$ water $(1-w)$ at 278.15 to $323.15 \mathrm{~K}$ under 101.1 $\mathrm{kPa}^{\mathrm{a}}$

\begin{tabular}{|c|c|c|c|c|c|c|c|c|c|c|c|}
\hline \multirow{2}{*}{$T / \mathrm{K}$} & \multicolumn{11}{|l|}{$w$} \\
\hline & $\overline{0}$ & 0.1000 & 0.2010 & 0.3000 & 0.4011 & 0.5012 & 0.6000 & 0.7002 & 0.7988 & 0.9000 & 1.000 \\
\hline 278.15 & 0.01074 & 0.04798 & 0.1158 & 0.1872 & 0.2618 & 0.3435 & 0.4394 & 0.5424 & 0.7059 & 0.8183 & 0.9409 \\
\hline 283.15 & 0.01378 & 0.05934 & 0.1395 & 0.2213 & 0.2987 & 0.3907 & 0.4874 & 0.6139 & 0.7774 & 0.8898 & 1.006 \\
\hline 288.15 & 0.01737 & 0.07285 & 0.1686 & 0.2651 & 0.3498 & 0.4418 & 0.5385 & 0.6548 & 0.8592 & 0.9920 & 1.165 \\
\hline 293.15 & 0.02180 & 0.08831 & 0.1993 & 0.3079 & 0.4111 & 0.5031 & 0.5998 & 0.7468 & 0.9614 & 1.094 & 1.228 \\
\hline 298.15 & 0.02755 & 0.1081 & 0.2389 & 0.3634 & 0.4638 & 0.5660 & 0.6855 & 0.8670 & 1.041 & 1.214 & 1.339 \\
\hline 303.15 & 0.03409 & 0.1313 & 0.2871 & 0.4352 & 0.5440 & 0.6564 & 0.7837 & 0.9614 & 1.156 & 1.401 & 1.606 \\
\hline 308.15 & 0.04184 & 0.1569 & 0.3374 & 0.5056 & 0.6281 & 0.7711 & 0.9236 & 1.096 & 1.310 & 1.576 & 1.770 \\
\hline 313.15 & 0.05139 & 0.1895 & 0.4043 & 0.6046 & 0.7177 & 0.8914 & 1.080 & 1.237 & 1.513 & 1.861 & 2.138 \\
\hline 318.15 & 0.06274 & 0.2254 & 0.4726 & 0.6985 & 0.8663 & 1.050 & 1.250 & 1.442 & 1.738 & 2.096 & 2.330 \\
\hline 323.15 & 0.07569 & 0.2663 & 0.5511 & 0.8086 & 1.013 & 1.207 & 1.464 & 1.683 & 2.010 & 2.398 & 2.624 \\
\hline
\end{tabular}

${ }^{\text {a }}$ Standard uncertainties $u$ are $u(T)=0.02 \mathrm{~K}, u(p)=0.12 \mathrm{KPa}$; Relative standard uncertainty $u_{\mathrm{r}}$ is $u_{\mathrm{r}}(x)=0.025, u_{r}(w)$

$=0.0002 . w$ represents the mass fraction of ethanol in solvent mixtures of ethanol + water. 


\section{Table 3}

Equilibrium mole fraction $\left(x_{T, w}^{e} \times 10^{3}\right)$ of 7-AMC in cosolvency EG $(w)+$ water $(1-w)$ at 278.15 to $323.15 \mathrm{~K}$ under $101.1 \mathrm{kPa}^{\mathrm{a}}$

\begin{tabular}{|c|c|c|c|c|c|c|c|c|c|c|c|}
\hline \multirow{2}{*}{$T / \mathrm{K}$} & \multicolumn{11}{|l|}{$w$} \\
\hline & $\overline{0}$ & 0.1003 & 0.2000 & 0.3011 & 0.3976 & 0.5000 & 0.6001 & 0.7006 & 0.8009 & 0.8979 & 1.000 \\
\hline 278.15 & 0.01074 & 0.03088 & 0.06002 & 0.09146 & 0.1314 & 0.1577 & 0.2042 & 0.2501 & 0.2830 & 0.3224 & 0.3836 \\
\hline 283.15 & 0.01378 & 0.03862 & 0.07370 & 0.1107 & 0.1420 & 0.1814 & 0.2269 & 0.2820 & 0.3280 & 0.3739 & 0.4320 \\
\hline 288.15 & 0.01737 & 0.04799 & 0.09087 & 0.1360 & 0.1683 & 0.2208 & 0.2729 & 0.3280 & 0.3871 & 0.4593 & 0.5310 \\
\hline 293.15 & 0.02180 & 0.05951 & 0.1120 & 0.1675 & 0.2011 & 0.2602 & 0.3189 & 0.4002 & 0.4725 & 0.5645 & 0.6627 \\
\hline 298.15 & 0.02755 & 0.07415 & 0.1385 & 0.2062 & 0.2365 & 0.3088 & 0.3937 & 0.4927 & 0.5847 & 0.6898 & 0.8124 \\
\hline 303.15 & 0.03409 & 0.09048 & 0.1677 & 0.2486 & 0.2865 & 0.3719 & 0.4700 & 0.5842 & 0.6893 & 0.8207 & 0.9739 \\
\hline 308.15 & 0.04184 & 0.1092 & 0.2000 & 0.2943 & 0.3517 & 0.4568 & 0.5736 & 0.7085 & 0.8333 & 0.9778 & 1.117 \\
\hline 313.15 & 0.05139 & 0.1320 & 0.2396 & 0.3504 & 0.4245 & 0.5427 & 0.6736 & 0.8207 & 0.9520 & 1.123 & 1.303 \\
\hline 318.15 & 0.06274 & 0.1582 & 0.2834 & 0.4103 & 0.5271 & 0.6650 & 0.8010 & 0.9591 & 1.104 & 1.275 & 1.454 \\
\hline 323.15 & 0.07569 & 0.1877 & 0.3324 & 0.4774 & 0.6489 & 0.8131 & 0.9713 & 1.141 & 1.299 & 1.463 & 1.632 \\
\hline
\end{tabular}

a Standard uncertainties $u$ are $u(T)=0.02 \mathrm{~K}, u(p)=0.12 \mathrm{KPa}$; Relative standard uncertainty $u_{\mathrm{r}}$ is $u_{\mathrm{r}}(x)=0.025, u_{r}(w)$

$=0.0002 . w$ represents the mass fraction of EGin solvent mixtures of EG + water. 


\section{Table 4}

Equilibrium mole fraction $\left(x_{T, w}^{e} \times 10^{3}\right)$ of 7-AMC in cosolvency isopropanol (w) + water (1-w) at 278.15 to 323.15 $\mathrm{K}$ under $101.1 \mathrm{kPa}^{\mathrm{a}}$

\begin{tabular}{|c|c|c|c|c|c|c|c|c|c|c|c|}
\hline \multirow{2}{*}{$T / \mathrm{K}$} & \multicolumn{11}{|l|}{$w$} \\
\hline & 0 & 0.1000 & 0.2001 & 0.3012 & 0.3989 & 0.5000 & 0.5986 & 0.7020 & 0.8006 & 0.9013 & 1.000 \\
\hline 278.15 & 0.01074 & 0.06436 & 0.1743 & 0.2880 & 0.3626 & 0.5082 & 0.5976 & 0.6953 & 0.7901 & 0.9088 & 1.033 \\
\hline 283.15 & 0.01378 & 0.07945 & 0.2099 & 0.3413 & 0.4250 & 0.5447 & 0.6551 & 0.7774 & 0.8960 & 1.015 & 1.139 \\
\hline 288.15 & 0.01737 & 0.09672 & 0.2502 & 0.4015 & 0.4960 & 0.6159 & 0.7500 & 0.8841 & 1.015 & 1.145 & 1.273 \\
\hline 293.15 & 0.02180 & 0.1181 & 0.3012 & 0.4806 & 0.5927 & 0.6989 & 0.8449 & 1.003 & 1.169 & 1.335 & 1.515 \\
\hline 298.15 & 0.02755 & 0.1447 & 0.3622 & 0.5716 & 0.7005 & 0.8038 & 0.9754 & 1.155 & 1.345 & 1.523 & 1.732 \\
\hline 303.15 & 0.03409 & 0.1731 & 0.4241 & 0.6600 & 0.8011 & 0.9197 & 1.099 & 1.296 & 1.497 & 1.687 & 1.878 \\
\hline 308.15 & 0.04184 & 0.2062 & 0.4960 & 0.7636 & 0.9207 & 1.038 & 1.242 & 1.462 & 1.675 & 1.865 & 2.083 \\
\hline 313.15 & 0.05139 & 0.2465 & 0.5841 & 0.8917 & 1.071 & 1.169 & 1.396 & 1.628 & 1.841 & 2.090 & 2.371 \\
\hline 318.15 & 0.06274 & 0.2923 & 0.6802 & 1.027 & 1.224 & 1.322 & 1.581 & 1.838 & 2.063 & 2.336 & 2.605 \\
\hline 323.15 & 0.07569 & 0.3441 & 0.7895 & 1.183 & 1.405 & 1.495 & 1.763 & 2.054 & 2.315 & 2.623 & 2.941 \\
\hline
\end{tabular}

a Standard uncertainties $u$ are $u(T)=0.02 \mathrm{~K}, u(p)=0.12 \mathrm{KPa}$; Relative standard uncertainty $u_{\mathrm{r}}$ is $u_{\mathrm{r}}(x)=0.025, u_{r}(w)$

$=0.0002 . w$ represents the mass fraction of isopropanol in solvent mixtures of isopropanol + water. 


\section{Table 5}

Equilibrium mole fraction $\left(x_{T, w}^{e} \times 10^{3}\right)$ of 7-AMC in cosolvency DMF $(w)+$ water $(1-w)$ at 278.15 to $323.15 \mathrm{~K}$ under $101.1 \mathrm{kPa}^{\mathrm{a}}$

\begin{tabular}{|c|c|c|c|c|c|c|c|c|c|c|c|}
\hline \multirow{2}{*}{$T / \mathrm{K}$} & \multicolumn{11}{|l|}{$w$} \\
\hline & $\overline{0}$ & 0.1002 & 0.2003 & 0.2990 & 0.4000 & 0.5000 & 0.6013 & 0.7001 & 0.7998 & 0.9009 & 1.000 \\
\hline 278.15 & 0.01074 & 0.3175 & 2.037 & 4.974 & 6.924 & 8.764 & 11.00 & 15.89 & 24.08 & 39.06 & 57.91 \\
\hline 283.15 & 0.01378 & 0.3886 & 2.444 & 5.950 & 8.081 & 10.11 & 14.02 & 18.25 & 32.45 & 54.24 & 72.53 \\
\hline 288.15 & 0.01737 & 0.4686 & 2.893 & 7.030 & 9.949 & 12.27 & 17.99 & 23.94 & 37.70 & 70.69 & 90.22 \\
\hline 293.15 & 0.02180 & 0.5616 & 3.395 & 8.208 & 12.03 & 14.42 & 19.39 & 27.97 & 47.48 & 79.84 & 108.2 \\
\hline 298.15 & 0.02755 & 0.6789 & 4.022 & 9.679 & 14.48 & 18.37 & 25.95 & 35.07 & 61.99 & 99.33 & 131.1 \\
\hline 303.15 & 0.03409 & 0.8048 & 4.677 & 11.21 & 17.22 & 21.01 & 27.32 & 42.05 & 67.59 & 114.0 & 156.0 \\
\hline 308.15 & 0.04184 & 0.9502 & 5.434 & 13.00 & 20.11 & 23.39 & 34.43 & 50.96 & 75.16 & 131.9 & 189.2 \\
\hline 313.15 & 0.05139 & 1.119 & 6.267 & 14.89 & 22.87 & 27.13 & 39.25 & 57.94 & 93.57 & 161.3 & 218.7 \\
\hline 318.15 & 0.06274 & 1.310 & 7.194 & 16.98 & 25.59 & 31.38 & 44.96 & 66.48 & 113.7 & 185.8 & 251.0 \\
\hline 323.15 & 0.07569 & 1.522 & 8.212 & 19.30 & 29.06 & 37.33 & 49.46 & 76.13 & 124.1 & 209.8 & 291.6 \\
\hline
\end{tabular}

a Standard uncertainties $u$ are $u(T)=0.02 \mathrm{~K}, u(p)=0.12 \mathrm{KPa}$; Relative standard uncertainty $u_{\mathrm{r}}$ is $u_{\mathrm{r}}(x)=0.025$, $u_{r}(w)=0.0002 . w$ represents the mass fraction of DMF in solvent mixtures of DMF + water. 


\section{Table 6}

The parameter values obtained from the selected thermodynamic cosolvency models in this study.

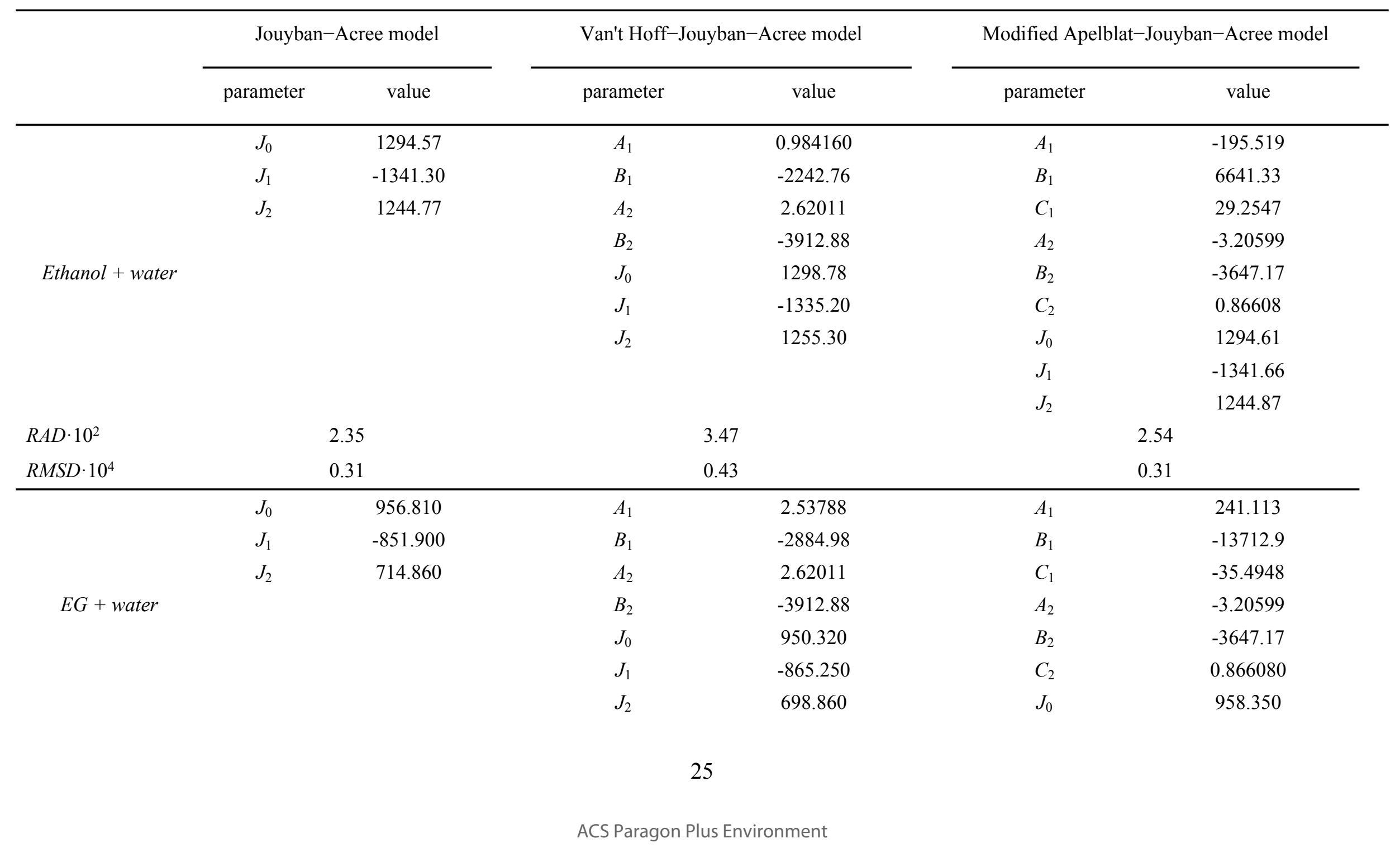




\begin{tabular}{|c|c|c|c|c|c|c|}
\hline & & & & & $\begin{array}{l}J_{1} \\
J_{2}\end{array}$ & $\begin{array}{r}-849.510 \\
718.690\end{array}$ \\
\hline$R A D \cdot 10^{2}$ & \multicolumn{2}{|c|}{2.52} & \multicolumn{2}{|c|}{3.00} & \multicolumn{2}{|c|}{3.13} \\
\hline$R M S D \cdot 10^{4}$ & \multicolumn{2}{|c|}{0.21} & \multicolumn{2}{|c|}{0.22} & \multicolumn{2}{|c|}{0.22} \\
\hline \multirow{9}{*}{$\begin{array}{c}\text { Isopropanol + } \\
\text { water }\end{array}$} & $J_{0}$ & 1608.67 & $A_{1}$ & 0.721420 & $A_{1}$ & -19.2288 \\
\hline & $J_{1}$ & -1771.77 & $B_{1}$ & -2119.61 & $B_{1}$ & -1218.33 \\
\hline & $J_{2}$ & 1524.80 & $A_{2}$ & 2.62011 & $C_{1}$ & 2.97051 \\
\hline & & & $B_{2}$ & -3912.88 & $A_{2}$ & -3.20599 \\
\hline & & & $J_{0}$ & 1609.29 & $B_{2}$ & -3647.17 \\
\hline & & & $J_{1}$ & -1772.22 & $C_{2}$ & 0.86608 \\
\hline & & & $J_{2}$ & 1526.34 & $J_{0}$ & 1608.61 \\
\hline & & & & & $J_{1}$ & -1772.29 \\
\hline & & & & & $J_{2}$ & 1524.65 \\
\hline$R A D \cdot 10^{2}$ & \multicolumn{2}{|c|}{3.25} & \multicolumn{2}{|c|}{3.40} & \multicolumn{2}{|c|}{3.36} \\
\hline$R M S D \cdot 10^{4}$ & \multicolumn{2}{|c|}{0.52} & \multicolumn{2}{|c|}{0.52} & \multicolumn{2}{|c|}{0.52} \\
\hline \multirow{10}{*}{$D M F+$ water } & $J_{0}$ & 2682.10 & $A_{1}$ & 8.47189 & $A_{1}$ & 120.857 \\
\hline & $J_{1}$ & -3753.53 & $B_{1}$ & -3132.86 & $B_{1}$ & -8238.54 \\
\hline & $J_{2}$ & 3299.87 & $A_{2}$ & 2.62011 & $C_{1}$ & -16.7178 \\
\hline & & & $B_{2}$ & -3912.88 & $A_{2}$ & -3.20599 \\
\hline & & & $J_{0}$ & 2678.39 & $B_{2}$ & -3647.17 \\
\hline & & & $J_{1}$ & -3761.85 & $C_{2}$ & 0.866080 \\
\hline & & & $J_{2}$ & 3290.65 & $J_{0}$ & 2682.70 \\
\hline & & & & & $J_{1}$ & -3752.86 \\
\hline & & & & & $J_{2}$ & 3301.35 \\
\hline & \multicolumn{4}{|c|}{26} & & \\
\hline
\end{tabular}




\begin{tabular}{|c|c|c|c|}
\hline$R A D \cdot 10^{2}$ & 1.88 & 2.44 & 1.97 \\
\hline$R M S D \cdot 10^{4}$ & 15.20 & 17.89 & 14.50 \\
\hline
\end{tabular}




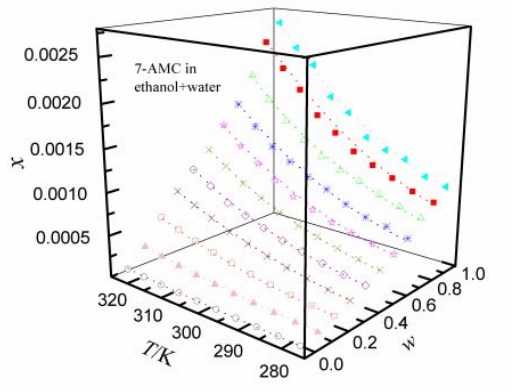

For Table of Contents Only 